\title{
Postoperative infection in spine surgery: does the month matter?
}

\author{
Michael J. Durkin, MD,,2 Kristen V. Dicks, MD,,2 Arthur W. Baker, MD,,2 \\ Rebekah W. Moehring, MD, MPH, ${ }^{1-3}$ Luke F. Chen, MBBS, MPH, ${ }^{1,2}$ Daniel J. Sexton, MD, ${ }^{1,2}$ \\ Sarah S. Lewis, MD, MPH, ${ }^{1,2}$ and Deverick J. Anderson, MD, MPH ${ }^{1,2}$
}

${ }^{1}$ Department of Medicine, Division of Infectious Diseases, Duke University Medical Center; ${ }^{2}$ Duke Infection Control Outreach Network; and ${ }^{3}$ Durham VA Medical Center, Durham, North Carolina

\begin{abstract}
OBJECT The relationship between time of year and surgical site infection (SSI) following neurosurgical procedures is poorly understood. Authors of previous reports have demonstrated that rates of SSI following neurosurgical procedures performed during the summer months were higher compared with rates during other seasons. It is unclear, however, if this difference was related to climatological changes or inexperienced medical trainees (the July effect). The aim of this study was to evaluate for seasonal variation of SSI following spine surgery in a network of nonteaching community hospitals.
\end{abstract}

METHODS The authors analyzed 6 years of prospectively collected surveillance data (January 1, 2007, to December 31,2012 ) from all laminectomies and spinal fusions from 20 hospitals in the Duke Infection Control Outreach Network of community hospitals. Surgical site infections were defined using National Healthcare Safety Network criteria and identified using standardized methods across study hospitals. Regression models were then constructed using Poisson distribution to evaluate for seasonal trends by month. Each analysis was first performed for all SSIs and then for SSIs caused by specific organisms or classes of organisms. Categorical analysis was performed using two separate definitions of summer: June through September (definition 1), and July through September (definition 2). The prevalence rate of SSIs during the summer was compared with the prevalence rate during the remainder of the year by calculating prevalence rate ratios and $95 \%$ confidence intervals.

RESULTS The authors identified 642 SSIs following 57,559 neurosurgical procedures (overall prevalence rate = $1.11 / 100$ procedures); 215 occurred following 24,466 laminectomies (prevalence rate $=0.88 / 100$ procedures), and 427 following 33,093 spinal fusions (prevalence rate $=1.29 / 100$ procedures). Common causes of SSI were Staphylococcus aureus ( $n=380 ; 59 \%)$, coagulase-negative staphylococci $(n=90 ; 14 \%)$, and Escherichia coli $(n=41 ; 6.4 \%)$. Poisson regression models demonstrated increases in the rates of SSI during each of the summer months for all SSIs and SSIs due to gram-positive cocci, $S$. aureus, and methicillin-sensitive $S$. aureus. Categorical analysis confirmed that the rate of SSI during the 4-month summer period was higher than the rate during the remainder of the year, regardless of which definition for summer was used (definition 1, $p=0.008$; definition 2, $p=0.003$ ). Similarly, the rates of SSI due to grampositive cocci and $S$. aureus were higher during the summer months than the remainder of the year regardless of which definition of summer was used. However, the rate of SSI due to gram-negative bacilli was not.

CONCLUSIONS The rate of SSI following fusion or spinal laminectomy/laminoplasty was higher during the summer in this network of community hospitals. The increase appears to be related to increases in SSIs caused by gram-positive cocci and, more specifically, S. aureus. Given the nonteaching nature of these hospitals, the findings demonstrate that increases in the rate of SSI during the summer are more likely related to ecological and/or environmental factors than the July effect.

http://thejns.org/doi/abs/10.3171/2014.10.SPINE14559

KEY WORDS surgical site infection; spinal fusion; laminectomy; seasonality; July effect; spine surgery

ABBREVIATIONS CI = confidence interval; DICON = Duke Infection Control Outreach Network; MRSA = methicillin-resistant Staphylococcus aureus; MSSA = methicillinsensitive Staphylococcus aureus; NHSN = National Healthcare Safety Network; SSI = surgical site infection.

SUBMITTED June 10, 2014. ACCEPTED October 23, 2014.

INCLUDE WHEN CITING Published online April 10, 2015; DOI: 10.3171/2014.10.SPINE14559.

DISCLOSURE Dr. Anderson was supported by NIH grant no. K23AI095357. Dr. Sexton has served as a consultant to Johnson \& Johnson. 
$\mathrm{S}$ URGICAL site infections (SSIs) lead to devastating patient outcomes. Surgical site infections are associated with a 5-fold increase in risk of readmission, a 2-fold increase in postoperative deaths, and additional societal costs from resultant chronic conditions and missed economic opportunities. ${ }^{15,18,23}$ While there are well-established risk factors for postoperative SSI following spine surgery, ${ }^{30}$ some potential risk factors remain inadequately addressed. Specifically, the relationship between seasonality, surgeon experience, and the risk of SSI is controversial..$^{37}$

The prevalence of some bacterial infections is associated with season of the year. For example, infections caused by gram-negative bacteria such as Escherichia coli, Acinetobacter baumanii, Pseudomonas auregino$s a$, and Enterobacter cloacae occur more frequently in warmer summer and fall months than the remainder of the year. ${ }^{13,24,29,31,33}$ Similarly, skin and soft-tissue infections caused by Staphylococcus aureus occur more frequently in the summer, $, 24,36$ while pneumonia due to methicillinresistant S.aureus (MRSA) may occur more frequently in the winter. ${ }^{16,19,35}$

Inexperienced surgeons have higher surgical complication rates. ${ }^{14,25}$ Inexperienced surgical house staff may have higher rates of SSIs during their first few months in training. ${ }^{4,5,22,26}$ For example, Raval et al. observed that resident involvement was associated with a $21.2 \%$ higher SSI rate in general and with vascular surgery procedures (5.34/100 procedures vs $3.47 / 100$ procedures, respectively; $\mathrm{p}<0.0001) .{ }^{32}$ The association between new house staff and increased risk of adverse patient outcomes has been labeled as the July effect.

To date, few studies have examined the seasonality of SSI following neurosurgical procedures. Gruskay et al. recently studied more than 8100 spine surgeries between 2005 and 2009 at a single tertiary referral institution..$^{15}$ First, the authors noted a significantly higher rate of SSI during the summer months, defined as July through September $(p=0.03)$. Second, the rate of SSIs more than doubled when comparing the experienced outgoing house staff in June to inexperienced incoming ones in July ( $\mathrm{p}=$ 0.02 ). Ultimately, the authors were unable to determine if the higher SSI rate observed during the summer was related to house staff experience or seasonal variation. Thus, the objective of our study was to determine if the rate of SSI following spinal procedures varies by season in nonteaching community hospitals.

\section{Methods \\ Study Population}

The Duke Infection Control Outreach Network (DICON) is a network of community hospitals in the Southeastern US that has been described previously. ${ }^{2}$ In brief, DICON provides infection control consultation and educational services to more than 40 hospitals in 5 states. Infection preventionists at each hospital use standardized National Healthcare Safety Network (NHSN) definitions to prospectively identify cases of SSI. ${ }^{27}$ Cases are identified through review of microbiology records, hospital readmissions, and postdischarge questionnaires. These methods have been previously validated..$^{20,21}$ Infection preventionists prospectively enter demographic, clinical, surgical, and microbiological data into a local database. Identifiers are removed from the data prior to transmission to a centralized DICON surgical database. As a result, this study was considered research not involving human subjects by the Duke University Health System Institutional Review Board.

We performed a retrospective analysis of surveillance data collected between January 1, 2007, and December 31, 2012, from 20 DICON-affiliated hospitals (median size 291 beds, range 50-490 beds). These 20 hospitals were selected because they had complete surgical surveillance data for the entire 6-year study period. The excluded hospitals had similar demographics (median size 224 beds, range $18-481$ beds) and only represented $16 \%$ of total procedures in our cohort. All spinal fusion, laminectomy, and laminoplasty procedures, as identified by NHSN criteria, ${ }^{7}$ were included in our analysis. Basic demographic information including age, sex, race, procedure type, surgical risk index, and risk classification were collected. Prevalence rates for SSI were calculated as the number of SSIs per 100 procedures.

\section{Seasonality and SSI}

We evaluated the seasonality of SSI following spine surgery using Poisson regression. We constructed generalized estimating equation models using Poisson distribution to compare rates of SSI during summer months versus rates of SSI during nonsummer months by calculating prevalence rates, prevalence rate ratios, and 95\% confidence intervals (CIs). Overdispersion was observed in these models and corrected using the Pearson chi-square as the dispersion parameter. We tested for seasonality using two definitions of "summer." The first definition included June through September, as these are the 4 hottest months of the year in North Carolina, with the average temperature in June being equivalent to the average temperature in September (http://www.usclimatedata.com/ climate/raleigh/north-carolina/united-states/usnc0558). The second definition included July through September (summer solstice to fall equinox), which corresponds to the conventional definition of summer used in other studies. ${ }^{3,10,15,29}$ We performed these two sets of analyses to test for seasonality for all cases of SSI, for SSIs due to grampositive organisms, and for SSIs due to gram-negative organisms. We then constructed models with month as a continuous dependent variable, using first-, second-, and third-order polynomial terms to visualize trends. Finally, we compared the characteristics of cases performed in "summer" to cases performed during the rest of the year to determine if the patient populations and types of cases were different. Similarly, we compared average operative duration between the two groups to evaluate for potential confounding from trauma or complex cases.

\section{Statistical Analysis}

Statistical analyses were performed using SAS (version 9.3, SAS Institute). Categorical variables were compared using chi-square or Fisher exact tests; continuous variables were compared using the Student t-test or Wilcoxon 
rank-sum test, as appropriate. Statistical significance was defined as a p value $<0.05$ and $95 \%$ CIs that do not contain a prevalence rate ratio of 1.00 .

\section{Results}

A total of 642 SSIs were observed following 57,559 spine surgeries during the 6-year study period (overall rate 1.11/100 procedures); 427 SSIs occurred following 33,093 spinal fusion surgeries (rate $=1.29 / 100$ procedures); and 215 SSIs occurred following 24,466 laminectomies (rate = $0.88 / 100$ procedures; Table 1 ). The median age of surgical patients was 54 years; 9191 (78\%) were white and 23,270 (51\%) were female. Gram-positive cocci caused almost $80 \%$ of infections. Patients who underwent spinal surgical procedures in the summer were similar to patients who underwent their procedures during other times of the year, regardless of whether summer was defined as June through September or July through September (Table 1).
S. aureus was the most common cause of SSI following spinal procedures (Table 2).

\section{Analyses of all SSIs}

The rate of SSI following spinal procedures varied by month according to polynomial regression analysis (Fig. 1). In particular, the projected rates were highest during the summer months. Categorical analyses confirmed this finding regardless of which of the two definitions for summer were used (Table 3). Using the definition of June through September for summer, the prevalence rate of SSI was significantly higher in summer compared with the rest of the year: $1.28 / 100$ procedures (95\% CI 1.12-1.44) versus $1.03 / 100$ procedures (95\% CI $0.93-1.13$ ), respectively, prevalence rate ratio 1.24 (95\% CI 1.06-1.45), $\mathrm{p}=0.008$. Using the definition of July through September for summer, the rate of SSI was significantly higher in summer compared with the rest of the year: $1.33 / 100$ procedures

TABLE 1. Perioperative characteristics of patients undergoing spine surgery in DICON community hospitals overall and by season (January 1, 2007, to December 31, 2012)

\begin{tabular}{|c|c|c|c|c|}
\hline Variables & Overall & June-September & October-May & p Value \\
\hline No. of patients & 57,559 & 18,957 & 38,602 & \\
\hline Median age in yrs (IQR) & $54(44-65)$ & $54(44-65)$ & $54(44-64)$ & 0.18 \\
\hline Median operation duration in mins (IQR) & $113(74-179)$ & $112(74-179)$ & $113(74-178)$ & 0.30 \\
\hline $\operatorname{Sex}(\%)$ & & & & $0.13^{*}$ \\
\hline Male & $22,691(49)$ & $7382(49)$ & $15,309(50)$ & \\
\hline Female & $23,270(51)$ & $7723(51)$ & $15,547(50)$ & \\
\hline Race (\%) & & & & $0.82^{*}$ \\
\hline White & $9191(78)$ & $2902(78)$ & $6289(78)$ & \\
\hline Black & $2244(19)$ & $699(19)$ & $1521(19)$ & \\
\hline Other & $316(3)$ & $105(3)$ & $211(3)$ & \\
\hline Procedure (\%) & & & & 0.25 \\
\hline Laminectomy & $24,466(42)$ & $8122(43)$ & $16,344(42)$ & \\
\hline Spinal fusion & $33,093(58)$ & $10,835(57)$ & $22,258(58)$ & \\
\hline NHSN risk index (\%) & & & & $0.37^{*}$ \\
\hline 0 & $28,605(50)$ & $9382(49)$ & $19,223(50)$ & \\
\hline 1 & $23,496(41)$ & 7807 (41) & $15,689(41)$ & \\
\hline 2 & $5414(9)$ & $1756(9)$ & $3661(10)$ & \\
\hline 3 & $44(0.08)$ & $15(0.08)$ & $29(0.08)$ & \\
\hline ASA classification (\%)† & & & & $0.48^{*}$ \\
\hline 1 & $3884(7)$ & $1319(7)$ & $2565(7)$ & \\
\hline 2 & $30,186(52)$ & $9863(52)$ & $20,343(53)$ & \\
\hline 3 & $21,443(37)$ & $7110(37)$ & $14,333(37)$ & \\
\hline 4 & $2031(4)$ & $661(4)$ & $1370(4)$ & \\
\hline 5 & $15(0.03)$ & $4(0.02)$ & $11(0.03)$ & \\
\hline Infection class (\%)‡ & & & & $0.19^{*}$ \\
\hline Superficial incisional & $185(29)$ & $77(32)$ & $108(27)$ & \\
\hline Deep incisional & $352(55)$ & $123(51)$ & $229(57)$ & \\
\hline Organ/space & $104(16)$ & $42(17)$ & $62(16)$ & \\
\hline
\end{tabular}


TABLE 2. Summary of 642 SSIs following spine surgery isolated in 20 community hospitals by organism*

\begin{tabular}{cc}
\hline \multicolumn{1}{c}{ Organism } & Value (\%) \\
\hline Gram-positive cocci & $502(78)$ \\
\hline S. aureus & $380(59)$ \\
\hline MSSA & $213(33)$ \\
\hline MRSA & $167(26)$ \\
\hline Coagulase-negative staphylococci & $90(14)$ \\
\hline Gram-negative rods & $119(19)$ \\
\hline E. coli & $41(6.4)$ \\
\hline Pseudomonas spp. & $23(3.6)$ \\
\hline Proteus spp. & $21(3.3)$ \\
\hline Yeast & $5(0.8)$ \\
\hline No pathogen identified & $45(7.0)$ \\
\hline
\end{tabular}

* Organisms from polymicrobial infections were counted in each category. List contains only the most commonly identified organisms.

(95\% CI $1.15-1.53)$ versus $1.04 / 100$ procedures $(95 \%$ CI $0.95-1.14)$, respectively, prevalence rate ratio 1.29 (95\% CI $1.09-1.52), \mathrm{p}=0.003$.

\section{Analyses of SSls Stratified by Pathogens}

The rates of SSI due to gram-positive organisms (Fig. 2A), S. aureus (Fig. 2B), and methicillin-sensitive $S$. aureus (MSSA; Fig. 2C) varied by month, with the highest rates during the summer months. The rate of SSI due to gram-negative pathogens also demonstrated statistically significant variation by month (Fig. 2D). However, the overall regression curve was suggestive of slightly higher SSI rates due to gram-negative pathogens during the nonsummer months. Categorical analyses confirmed statistically significant findings for gram-positive cocci, S. aureus, and MSSA regardless of the definition of summer used, while gram-negative organisms were not statistically significant (Table 3 ).

\section{Discussion}

Our large, multicenter study demonstrated that rates of SSIs after spinal procedures performed at nonteaching hospitals are highest during the summer months. The increase appears to be caused by an increase in the rate of SSIs due to gram-positive cocci and, in particular, $S$. aureus. To our knowledge, our study presents two "firsts" in the surgical literature. Our study is the first to demonstrate seasonal variation in SSIs following spine surgery in community hospitals; and due to the absence of trainees in our hospital network, our study is the first to confirm seasonal variation of SSIs following spine surgery in the absence of the July effect.

Several other, nonsurgical S. aureus infections peak during the summer. In fact, Leekha et al. performed a systematic review on $S$. aureus epidemiology and found that 31/41 (76\%) of studies on S. aureus infection or colonization varied based on season. ${ }^{24}$ In particular, all 10 studies that specifically addressed skin and soft-tissue infections noted higher rates between summer and autumn. Similarly,

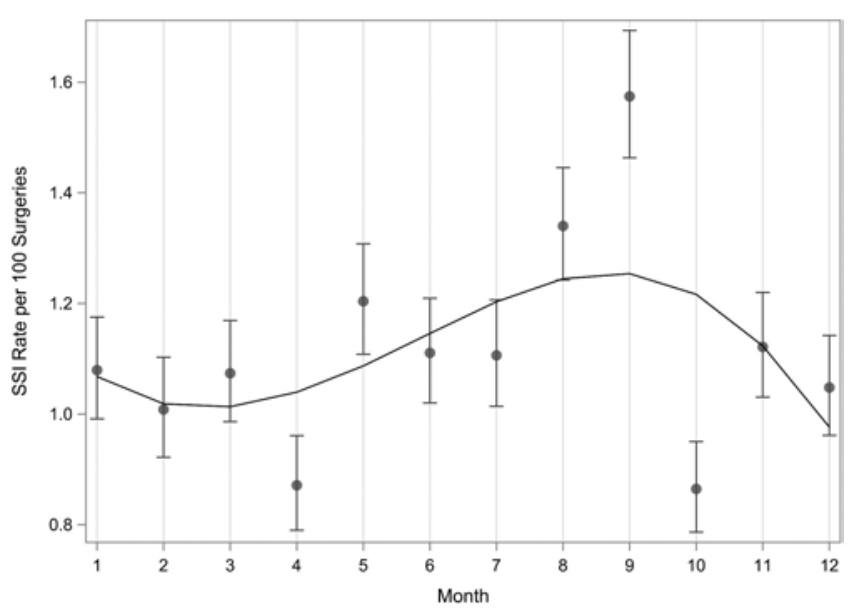

FIG. 1. Surgical site infection prevalence rate per 100 surgeries by month for all organisms. Polynomial regression analysis resulted in a best-fit line that showed statistically significant seasonal variation with the highest SSI prevalence rate during the summer months.

a recent time series analysis of 51,287 pediatric skin and soft-tissue infection clinical encounters found that rates of $S$. aureus infection were highest in the summer months. ${ }^{36}$

Seasonal variation of $S$. aureus infections may occur for several reasons. Specifically, investigators have found a statistically significant correlation between both temperature and humidity and S. aureus skin and soft-tissue infections. ${ }^{36} \mathrm{McBride}$ et al. found that $S$. aureus bacterial populations on the skin are significantly higher during warm and humid months. ${ }^{28}$ Skin-to-skin contact, which plays a large role in the nosocomial transmission of S. aureus, increases in frequency during the late summer. ${ }^{17}$ In addition, skin disruption from contact sports and insect bites occur during the summer and may contribute to $S$. aureus infections. ${ }^{34}$ Finally, summer months also have higher rates of trauma-related admissions, a known risk factor for SSI. ${ }^{15}$

Surprisingly, our study demonstrated no conclusive correlation between gram-negative rod infections and season. Several studies have previously demonstrated an increase in bloodstream infections, urinary tract infections, and dialysis-associated peritonitis due to gram-negative rod in the warmer, summer months. ${ }^{3,8,12}$ Proposed risk factors for the increase in gram-negative rod infections in the summer are generally similar to risk factors for $S$. aureus infections, including temperature, humidity, and possibly human behavior (e.g., dietary habits and recreational activities). ${ }^{6,10,11,13}$ For example, Ramos et al. concluded that the incidence of Pseudomonas aeruginosa infections in a 660-bed tertiary care medical center in Brazil increased with climatic changes. Urinary tract infections were associated with higher precipitation $(\mathrm{p}=0.04)$ and temperature $(\mathrm{p}=0.02)$, while hospital-acquired pneumonia was associated with humidity $(\mathrm{p}=0.03)$ and precipitation $(\mathrm{p}=$ 0.03). ${ }^{31}$ It is unclear why the rate of SSI in our network due to $S$. aureus increased in the summer but the rate of SSI due to gram-negative rods did not.

Our study has limitations. First, we included surveillance data with limited patient information available. Thus, we were unable to address multiple known risk fac- 
TABLE 3. Prevalence rates of SSIs following spine surgery with $95 \% \mathrm{Cls}$ for 2 separate definitions of summer

\begin{tabular}{clcccc}
\hline $\begin{array}{c}\text { Definition of } \\
\text { Summer }\end{array}$ & Organism & $\begin{array}{c}\text { Prevalence Rate for Summer } \\
(95 \% \mathrm{Cl})\end{array}$ & $\begin{array}{c}\text { Prevalence Rate for Rest } \\
\text { of } \mathrm{Yr}(95 \% \mathrm{Cl})\end{array}$ & $\begin{array}{c}\text { Prevalence Rate Ratio } \\
(95 \% \mathrm{Cl})\end{array}$ & $\begin{array}{c}\mathrm{pValue} \\
\text { June-September }\end{array}$ \\
& All SSIS & $1.28(1.12-1.44)$ & $1.03(0.93-1.13)$ & $1.24(1.06-1.45)$ & 0.008 \\
\hline & GPC & $1.02(0.88-1.16)$ & $0.80(0.71-0.89)$ & $1.27(1.06-1.52)$ & 0.008 \\
\hline & S. aureus & $0.78(0.66-0.91)$ & $0.60(0.52-0.68)$ & $1.06(1.06-1.60)$ & 0.01 \\
\hline & MSSA & $0.48(0.38-0.58)$ & $0.32(0.26-0.37)$ & $1.52(1.16-1.99)$ & 0.002 \\
\hline & MRSA & $0.30(0.22-0.38)$ & $0.28(0.23-0.34)$ & $1.06(0.77-1.46)$ & 0.74 \\
\hline & GNR & $0.20(0.13-0.26)$ & $0.21(0.17-0.26)$ & $0.92(0.62-1.35)$ & 0.47 \\
\hline July-September & & & & $1.29(1.09-1.52)$ & 0.003 \\
\hline & All SSIs & $1.33(1.15-1.53)$ & $1.04(0.95-1.14)$ & $1.28(1.06-1.55)$ & 0.01 \\
\hline & GPC & $1.04(0.88-1.21)$ & $0.82(0.73-0.90)$ & $1.28(1.03-1.59)$ & 0.03 \\
\hline & S. aureus & $0.79(0.64-0.94)$ & $0.62(0.54-0.69)$ & $1.37(1.03-1.83)$ & 0.03 \\
\hline & MSSA & $0.47(0.35-0.58)$ & $0.34(0.28-0.39)$ & $1.16(0.83-1.63)$ & 0.38 \\
\hline & MRSA & $0.32(0.23-0.42)$ & $0.28(0.23-0.33)$ & $1.12(0.75-1.69)$ & 0.57 \\
\hline
\end{tabular}

GNR = gram-negative rods; $G P C=$ gram-positive cocci.
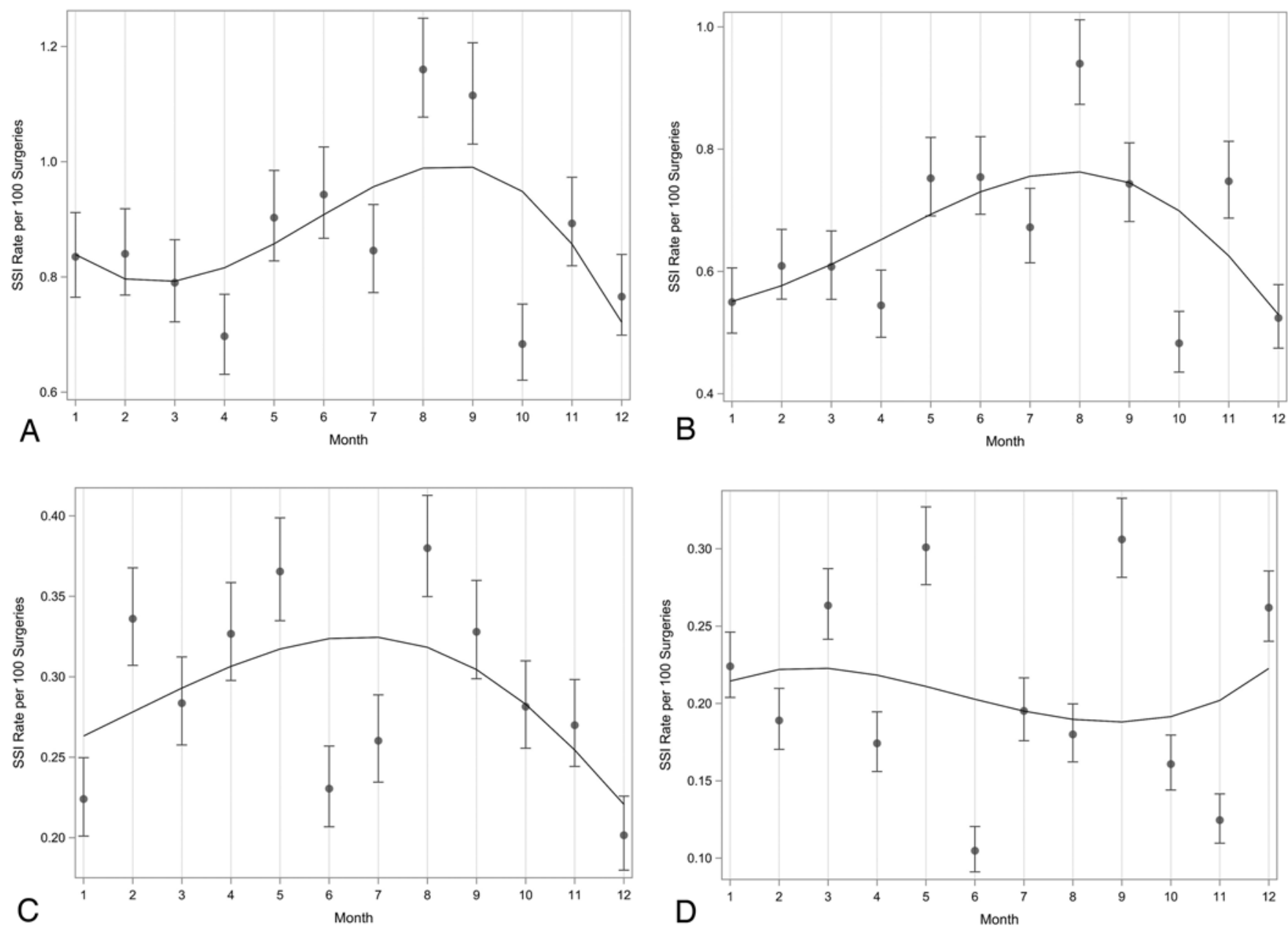

FIG. 2. Surgical site infection rates per 100 surgeries by month for gram-positive cocci (A), S. aureus (B), MSSA (C), and gramnegative bacilli (D). Polynomial regression analysis resulted in a best-fit line that showed statistically significant seasonal variation with the highest SSI prevalence rate during the summer months for gram-positive cocci (A), S. aureus (B), and MSSA (C), and during the nonsummer months for gram-negative bacilli (D). 
tors for SSI following spine surgery, including diabetes mellitus, prior SSI, and presence of obesity. In contrast, our analysis included prospectively collected, validated data from a large cohort. We analyzed several risk factors for SSI, including the American Society of Anesthesiologists index, which takes into account significant systemic diseases such as diabetes or severe obesity, and found no differences in patient populations. Second, we were unable to determine which surgical procedures were considered to be emergency surgery. Emergency surgeries are more likely to take place during the summer, have longer operative durations, and may be associated with an increased risk of SSI. However, there were no statistically significant differences in operative durations and start times between summer and other seasons in our study (data not shown). Third, our study was limited by a relatively low number of SSIs due to gram-negative bacilli. Therefore, our study may have lacked the power to detect seasonal variation in gram-negative bacilli infections. Fourth, our study only assessed the association between season and SSIs. The specific underlying risk factors that contribute to this association remain unknown. Without understanding the specific underlying risk factors, we are unable to give specific recommendations to surgeons on how this information can be used to reduce the incidence of SSIs. We consider our findings to be "hypothesis generating" and, as such, an important step forward regarding our knowledge of the risks of SSI. Finally, our findings can only be generalized to community hospitals. Of note, however, the majority of health care in the US is provided in these hospitals, ${ }^{1}$ and Gruskay et al. found similar seasonal trends in an academic medical center. ${ }^{15}$

\section{Conclusions}

Our multicenter study is the first to evaluate the seasonality of SSIs following spinal procedures performed in a network of nonteaching community hospitals. This trend was largely due to SSIs caused by gram-positive cocci and $S$. aureus. Due to the absence of trainees in our hospital network, we believe the higher rate of SSIs after spine surgery in our study is unrelated to the July effect. Instead, our data support the concept that climatological, social, and/or other environmental factors contribute to a higher rate of SSIs during the summer months. It is unclear why SSIs due to gram-positive organisms are highest during warm summer months. Based on our analyses, we speculate that season-specific interventions to reduce the risk of gram-positive SSIs may be of value.

\section{References}

1. American Hospital Association: Fast Facts on US Hospitals. (http://www.aha.org/research/rc/stat-studies/fast-facts. shtml) [Accessed February 19, 2015]

2. Anderson DJ, Miller BA, Chen LF, Adcock LH, Cook E, Cromer AL, et al: The network approach for prevention of healthcare-associated infections: long-term effect of participation in the Duke Infection Control Outreach Network. Infect Control Hosp Epidemiol 32:315-322, 2011

3. Anderson DJ, Richet H, Chen LF, Spelman DW, Hung YJ, Huang AT, et al: Seasonal variation in Klebsiella pneumoniae bloodstream infection on 4 continents. J Infect Dis 197:752756,2008
4. Auerbach JD, Lonner BS, Antonacci MD, Kean KE: Perioperative outcomes and complications related to teaching residents and fellows in scoliosis surgery. Spine (Phila Pa 1976) 33:1113-1118, 2008

5. Banco SP, Vaccaro AR, Blam O, Eck JC, Cotler JM, Hilibrand AS, et al: Spine infections: variations in incidence during the academic year. Spine (Phila Pa 1976) 27:962-965, 2002

6. Barben J, Hafen G, Schmid J, Swiss Paediatric Respiratory Research Group: Pseudomonas aeruginosa in public swimming pools and bathroom water of patients with cystic fibrosis. J Cyst Fibros 4:227-231, 2005

7. Centers for Disease Control and Prevention: National Healthcare Safety Network Operative Procedures by Legacy and ICD-9 Codes. October 2010. (http://www.cdc. gov/nhsn/pdfs/operativeprocedures.pdf) [Accessed February 19, 2015]

8. Cho Y, Badve SV, Hawley CM, McDonald SP, Brown FG, Boudville N, et al: Seasonal variation in peritoneal dialysisassociated peritonitis: a multi-centre registry study. Nephrol Dial Transplant 27:2028-2036, 2012

9. Dailiana ZH, Rigopoulos N, Varitimidis SE, Poultsides L, Petinaki E, Malizos KN: Clinical and epidemiological features of upper-extremity infections caused by Staphylococcus aureus carrying the PVL gene: a four-year study in Greece. Med Sci Monit 14:CR511-CR514, 2008

10. Eber MR, Shardell M, Schweizer ML, Laxminarayan R, Perencevich EN: Seasonal and temperature-associated increases in gram-negative bacterial bloodstream infections among hospitalized patients. PLoS ONE 6:e25298, 2011

11. Edrington TS, Callaway TR, Ives SE, Engler MJ, Looper ML, Anderson RC, et al: Seasonal shedding of Escherichia coli O157:H7 in ruminants: a new hypothesis. Foodborne Pathog Dis 3:413-421, 2006

12. Falagas ME, Peppas G, Matthaiou DK, Karageorgopoulos DE, Karalis N, Theocharis G: Effect of meteorological variables on the incidence of lower urinary tract infections. Eur J Clin Microbiol Infect Dis 28:709-712, 2009

13. Freeman JT, Anderson DJ, Sexton DJ: Seasonal peaks in Escherichia coli infections: possible explanations and implications. Clin Microbiol Infect 15:951-953, 2009

14. Gang C, Haibo L, Fancai L, Weishan C, Qixin C: Learning curve of thoracic pedicle screw placement using the freehand technique in scoliosis: how many screws needed for an apprentice? Eur Spine J 21:1151-1156, 2012

15. Gruskay J, Smith J, Kepler CK, Radcliff K, Harrop J, Albert $\mathrm{T}$, et al: The seasonality of postoperative infection in spine surgery. J Neurosurg Spine 18:57-62, 2013

16. Hageman JC, Uyeki TM, Francis JS, Jernigan DB, Wheeler JG, Bridges CB, et al: Severe community-acquired pneumonia due to Staphylococcus aureus, 2003-04 influenza season. Emerg Infect Dis 12:894-899, 2006

17. Hens N, Ayele GM, Goeyvaerts N, Aerts M, Mossong J, Edmunds JW, et al: Estimating the impact of school closure on social mixing behaviour and the transmission of close contact infections in eight European countries. BMC Infect Dis 9:187, 2009

18. Jarvis WR: Selected aspects of the socioeconomic impact of nosocomial infections: morbidity, mortality, cost, and prevention. Infect Control Hosp Epidemiol 17:552-557, 1996

19. Kallen AJ, Reed C, Patton M, Arnold KE, Finelli L, Hageman J: Staphylococcus aureus community-onset pneumonia in patients admitted to children's hospitals during autumn and winter of 2006-2007. Epidemiol Infect 138:666-672, 2010

20. Kaye KS, Engemann JJ, Fulmer EM, Clark CC, Noga EM, Sexton DJ: Favorable impact of an infection control network on nosocomial infection rates in community hospitals. Infect Control Hosp Epidemiol 27:228-232, 2006 
21. Kaye KS, Sloane R, Sexton DJ, Schmader KA: Risk factors for surgical site infections in older people. J Am Geriatr Soc $\mathbf{5 4 : 3 9 1 - 3 9 6 , ~} 2006$

22. Kestle JR, Cochrane DD, Drake JM: Shunt insertion in the summer: is it safe? J Neurosurg 105 (3 Suppl):165-168, 2006

23. Kirkland KB, Briggs JP, Trivette SL, Wilkinson WE, Sexton DJ: The impact of surgical-site infections in the 1990s: attributable mortality, excess length of hospitalization, and extra costs. Infect Control Hosp Epidemiol 20:725-730, 1999

24. Leekha S, Diekema DJ, Perencevich EN: Seasonality of staphylococcal infections. Clin Microbiol Infect 18:927933, 2012

25. Lonner BS, Scharf C, Antonacci D, Goldstein Y, Panagopoulos G: The learning curve associated with thoracoscopic spinal instrumentation. Spine (Phila Pa 1976) 30:2835-2840, 2005

26. Lonner BS, Toombs CS, Hammouri Q, Terran JS, Karia RJ, Errico TJ: Effect of spine fellow training on operative outcomes, affirming graduated responsibility. Spine (Phila Pa 1976) 38:1869-1874, 2013

27. Mangram AJ, Horan TC, Pearson ML, Silver LC, Jarvis WR: Guideline for Prevention of Surgical Site Infection, 1999. Am J Infect Control 27:97-132, 1999

28. McBride ME, Duncan WC, Knox JM: The environment and the microbial ecology of human skin. Appl Environ Microbiol 33:603-608, 1977

29. Perencevich EN, McGregor JC, Shardell M, Furuno JP, Harris AD, Morris JG Jr, et al: Summer peaks in the incidences of Gram-negative bacterial infection among hospitalized patients. Infect Control Hosp Epidemiol 29:1124-1131, 2008

30. Pull ter Gunne AF, Hosman AJ, Cohen DB, Schuetz M, Habil $\mathrm{D}$, van Laarhoven CJ, et al: A methodological systematic review on surgical site infections following spinal surgery: part 1: risk factors. Spine (Phila Pa 1976) 37:2017-2033, 2012

31. Ramos GP, Rocha JL, Tuon FF: Seasonal humidity may influence Pseudomonas aeruginosa hospital-acquired infection rates. Int J Infect Dis 17:e757-e761, 2013

32. Raval MV, Wang X, Cohen ME, Ingraham AM, Bentrem DJ, Dimick JB, et al: The influence of resident involvement on surgical outcomes. J Am Coll Surg 212:889-898, 2011

33. Richet H: Seasonality in Gram-negative and healthcare-associated infections. Clin Microbiol Infect 18:934-940, 2012
34. Skull SA, Krause V, Coombs G, Pearman JW, Roberts LA: Investigation of a cluster of Staphylococcus aureus invasive infection in the top end of the Northern Territory. Aust $\mathbf{N} \mathbf{Z} \mathbf{~ J}$ Med 29:66-72, 1999

35. Tasher D, Stein M, Simões EA, Shohat T, Bromberg M, Somekh E: Invasive bacterial infections in relation to influenza outbreaks, 2006-2010. Clin Infect Dis 53:1199-1207, 2011

36. Wang X, Towers S, Panchanathan S, Chowell G: A population based study of seasonality of skin and soft tissue infections: implications for the spread of CA-MRSA. PLoS ONE 8:e60872, 2013

37. Wiese M, Krämer J, Bernsmann K, Ernst Willburger R: The related outcome and complication rate in primary lumbar microscopic disc surgery depending on the surgeon's experience: comparative studies. Spine J 4:550-556, 2004

\section{Author Contributions}

Conception and design: Durkin, Anderson. Acquisition of data: Durkin, Anderson. Analysis and interpretation of data: Durkin, Dicks, Baker, Anderson. Drafting the article: Durkin, Dicks, Baker, Anderson. Critically revising the article: all authors. Reviewed submitted version of manuscript: all authors. Approved the final version of the manuscript on behalf of all authors: Durkin. Statistical analysis: Durkin, Anderson. Administrative/techni$\mathrm{cal} /$ material support: Durkin, Sexton, Anderson. Study supervision: Sexton, Anderson.

\section{Supplemental Information}

\section{Previous Presentation}

A portion of this paper focusing specifically on S. aureus has been previously presented as a poster presentation at the Society for Healthcare Epidemiology of America Spring Conference, April 3-6, 2014, in Denver, Colorado.

\section{Correspondence}

Michael J. Durkin, Department of Medicine, Duke University Medical Center, 315 Trent Dr., Rm. 181, Durham, NC 27710. email: michael.durkin@dm.duke.edu. 